Eur. J. Mineral.

2015, 27, 81-90

Published online 21 October 2014

\title{
A micromorphological study on natural and folded sepiolite
}

\author{
MERCEDES SUÁREZ ${ }^{1, *}$, JUAN MORALES $^{2,3}$, ALMUdENA TORRES-PARDO ${ }^{4}$ and EMILIA GARCÍA-ROMERO ${ }^{3,5}$ \\ ${ }^{1}$ Departamento de Geología, Universidad de Salamanca, Plaza de la Merced s/n, 37008 Salamanca, Spain \\ *Corresponding author, e-mail: msuarez@usal.es \\ ${ }^{2}$ Institute for Photon Science and Synchrotron Radiation, Karlsruhe Institute of Technology, Hermann-von-Helmholtz- \\ Platz 1, 76344 Eggenstein-Leopoldshafen, Germany \\ ${ }^{3}$ Departamento de Cristalografía y Mineralogía, Universidad Complutense de Madrid, C/José Antonio Novais 2, \\ 28040 Madrid, Spain \\ ${ }^{4}$ Departamento de Química Inorgánica, Facultad de Químicas, Universidad Complutense (UCM), CEI Moncloa, \\ 28040 Madrid, Spain \\ ${ }^{5}$ Instituto de Geociencias (UCM-CSIC), 28040 Madrid, Spain
}

\begin{abstract}
A sepiolite from Grant County (USA) was studied with two objectives. First, from a purely methodological perspective, a comparative micromorphological study was conducted using two imaging techniques: high-resolution transmission electron microscopy (HR-TEM) and atomic-force microscopy (AFM). The second objective was to determine whether the structural change that occurred in sepiolite after heating over $500^{\circ} \mathrm{C}$ induced observable morphological changes. The fibrous morphology of sepiolite was observed; furthermore, bundles and rods were observed in both the TEM and AFM imagery. However, individual laths were easily observed by TEM but could only be deduced from the irregularities of the rod surfaces by AFM. A good approximation of the lath widths $(\sim 21 \mathrm{~nm})$ can be obtained from measurements using the two techniques, but AFM allows for the determination of the height of the rods $(\sim 31 \mathrm{~nm})$ and shows that the mesocrystals are tabular. The folding of the structure after heating was followed by XRD and HR-TEM. The precise measurements performed by HR-TEM and AFM on the folded sepiolite show the micromorphological change in the particles, which decrease in width after folding (from $\sim 21 \mathrm{~nm}$ to $\sim 18 \mathrm{~nm}$ ) in accord with the reduction of the unit cell.
\end{abstract}

Key-words: sepiolite; lath; rod; mesocrystal; HR-TEM; AFM; SEM; micromorphology; folded sepiolite.

\section{Introduction}

Sepiolite is a clay mineral with a large and growing number of industrial applications. It has inner channels and edge tunnels in its crystals, which can be used to absorb and adsorb different molecules. An in-depth review of the properties and uses of sepiolite can be found in Álvarez et al. (2011) and Ruiz-Hitzky et al. (2011).

The sepiolite structure was reported by Brauner \& Preisinger (1956), but this mineral has been redefined as an end-member of the continuous polysomatic series sepiolite-palygorskite (Suárez \& García-Romero, 2011, 2013). The structure of this fibrous clay mineral can be described as the union of polysomes that run parallel to the $c$ axis of the unit cell, along the fibre axis. Each polysome has a 2:1 structure and is jointed to its neighbour by a shared basal oxygen from the tetrahedral sheet. The basal planes of the tetrahedral sheets are continuous, but they have a periodic inversion of the apical oxygens, causing the interruption of the octahedral sheet and the existence of polysomes and channels. The interruption of the sepiolite octahedral sheet produces two different positions of $\mathrm{Mg}$, at the interior or edge of the polysome. In the edge position, $\mathrm{Mg}$ bonds with two water molecules called coordinated water. Three types of water can be therefore described in sepiolite: a variable number of zeolitic water molecules, which are located inside the channels; four coordinatedwater molecules per half unit cell (phuc), completing the coordination sphere of the terminal $\mathrm{Mg}$ atoms; and structural water that corresponds to the $\mathrm{OH}^{-}$groups of the octahedral sheets as phyllosilicate. These types of water are expressed in the ideal structural formula phuc: $\mathrm{Si}_{12} \mathrm{O}_{30} \mathrm{Mg}_{8}(\mathrm{OH})_{4}\left(\mathrm{OH}_{2}\right)_{4} w \mathrm{H}_{2} \mathrm{O}$. Bukas et al. (2013) undertook a synchronous ATR infrared and NIR-spectroscopy study of sepiolite and found that, upon drying, the number of zeolitic water molecules $(w)$ varied between 7-8 in a hydrated state $(>30 \%$ of relative humidity, $\mathrm{RH})$ and between $w=0-1$ in a dry state $(0 \% \mathrm{RH})$. Additionally, they also described an intermediate state in which $w=4-5$ is possible for $\mathrm{RH}=3-10 \%$.

The progressive heating of sepiolite leads to the release of the three types of water molecules at different temperatures. Frost \& Ding (2003) described three main temperature intervals by studying the thermal behaviour of four 
sepiolites. From room temperature to $120^{\circ} \mathrm{C}$, most zeolitic water is lost and dry sepiolite persists until $300^{\circ} \mathrm{C}$; at this temperature, half of the coordinated water is lost and the structure folds. The semi-anhydrous and folded sepiolite is stable until it reaches $530^{\circ} \mathrm{C}$, where upon the other half of the coordinated water is also lost and anhydrous sepiolite appears. These intervals support the structural modifications found by Post et al. (2007). For these authors, semianhydrous sepiolite is stable between $325-550^{\circ} \mathrm{C}$, and the continuous heating of sepiolite produces a decrease in both $a$ and $c$ parameters. Sánchez del Río et al. (2011) also showed the variability in the sepiolite cell parameters after heating to $225^{\circ} \mathrm{C}$.

The fibrous morphology of sepiolite is its main characteristic and has been described since the first studies of this mineral. Several words have been used to name the particles and the aggregates in an attempt to describe them: fibre, lath, rod, bundle, tape, strip, and so on. Recently, García-Romero \& Suárez (2013) proposed a simple nomenclature that is not only descriptive but also has a crystallographic element: lath is an individual crystal, rod is a group of individual crystals in crystallographic continuity (mesocrystal) that is formed by the aggregation of individual laths (GarcíaRomero \& Suárez, 2014), and a bundle is a group of laths or rods with subparallel $c$ axes.

The aim of this work was a micromorphological study of natural and heated sepiolite by mean of HR-TEM (High Resolution Transmission Electron Microscopy) and AFM (Atomic Force Microscopy).

\section{Materials and methods}

The sepiolite from Grant County (USA) was selected for this study due to its high purity. It is a massive and earthy sepiolite that is white in colour, very pure and compact. This specimen was studied in a previous work focused on the crystal-chemistry of sepiolite (García-Romero \& Suárez, 2010). The sepiolite from Grant County shows a low specific surface area $\left(79 \mathrm{~m}^{2} \mathrm{~g}^{-1}\right)$ due to the external surface $\left(73 \mathrm{~m}^{2} \mathrm{~g}^{-1}\right)$ and microporosity $\left(6 \mathrm{~m}^{2} \mathrm{~g}^{-1}\right)$, as shown in Suárez \& García-Romero (2012).

The micromorphological study was conducted using Scanning Electron Microscopy (SEM-FEG), High Resolution Transmission Electron Microscopy (HRTEM) and Atomic Force Microscopy (AFM) at the Centro Nacional de Microscopía Electrónica (Spain). The SEMFEG observations were conducted using a JEOL JSM6335F (Field Emission Gum Scanning Electron Microscope) operating at $10 \mathrm{kV}$ and a working distance of $15 \mathrm{~mm}$. Prior to the SEM-FEG examination, freshly fractured surfaces of representative samples were airdried and coated with Au in vacuum.

For the other studies, the sample was powdered in a manual agate mortar. The TEM observations were performed by depositing a drop of dilute clay suspension onto a microscope grid with cellulose acetate butyrate and by viewing it with a JEOL 2000 FX microscope equipped with a double-tilt sample holder (up to a maximum of $\pm 45^{\circ}$ ) at an acceleration voltage of $200 \mathrm{kV}$ with a $0.5 \mathrm{~mm}$ zeta-axis displacement and $0.31 \mathrm{~nm}$ point-topoint resolution. High-resolution TEM images (HRTEM) were obtained with a JEOL 3000 FX Field Emission Microscope at an acceleration voltage of 300 $\mathrm{kV}$ with $0.17 \mathrm{~nm}$ point-to-point resolution equipped with a double-tilt sample holder (up to a maximum of $\pm 23^{\circ}$ ) and a CCD camera for digitally recording the images. Low electron beam doses were used to obtain the HRTEM images to prevent beam-damage to the samples. Special attention was paid to the natural sepiolite sample due to its higher sensitivity to beam-damage. The experimental conditions of the image acquisition were optimized to avoid structural modification as a result of the beam interaction, using a low beam intensity (below 500 counts on the CCD camera) with an exposition time of 0.8 $\mathrm{s}$ for the image acquisition.

The diluted suspension was prepared in the same fashion for the TEM and AFM studies to ensure that the preparation did not influence the results. For the AFM studies, a drop of dilute clay suspension was placed on a fresh cleaved mica surface and dried in a Petri dish under regular room conditions (Pinner et al., 2003). The AFM can provide three-dimensional information of the surface at a scale that cannot be provided by SEM or by TEM. The AFM observations were conducted in air with a commercial multimode Nanoscope IIIA of Digital Instruments. All of the images were obtained in contact mode, and both the height and deflection images were recorded. Silicon nitride tips (Veeco NP-S10) with a nominal force constant of $k=$ $0.06-0.58 \mathrm{~N} / \mathrm{m}$ were used. The image processing and measurements were performed using a Nanoscope with off-line software (version V5.30 R3SR3, Digital Instruments, Inc.) and with WSxM freeware (Horcas et al., 2007). To normalize the measurements, each height and width measurement was obtained in the same way.

The use of Atomic Force Microscopy is relatively recent for clay minerals studies, and this technique has been used for sepiolite studies on few occasions (Pinner et al., 2003; Alkan \& Benlikaya, 2008; Ökte \& Sayinöz, 2008; Benli et al., 2012; Miltner et al., 2012, among others). The only morphological study on sepiolite using AFM (Can et al., 2010) investigated the size variation of sepiolite from Sivrihiser (Turkey) in relation to the stirring time of a suspension. In this study, the higher the stirring time, the lower the particle width, indicating the aggregation of particles in the natural sample, and the most isolated particles measured were short ( $\sim 1000 \mathrm{~nm}$ in length), at 130 $\mathrm{nm}$ in width and $25 \mathrm{~nm}$ in height.

A portion of the powdered sample was heated for $3 \mathrm{~h}$ at $350^{\circ} \mathrm{C}$ and $550^{\circ} \mathrm{C}$, with a heating rate of $10^{\circ} / \mathrm{min}$, to study the possible variations in the particles after heating. X-ray powder diffraction patterns from the natural and heated samples were obtained using Siemens D-500 equipment, with $\mathrm{Cu} K \alpha$ radiation. The sample heated at $550^{\circ} \mathrm{C}$ was also studied by TEM and AFM. 


\section{Results}

\section{Natural sepiolite}

Like most sepiolites, sepiolite from Grant County is an earthy-sepiolite and therefore the use of electron microscopy is required to study its morphological features. The use of SEM-FEG allows for the study of the texture of the sample and the gathering of information regarding the morphology from a 2D image. This sepiolite has a very open texture in which the fibrous morphology is observed under smaller magnification (Fig. 1a, b, c and d). The length of the fibres is normally more than $10 \mu \mathrm{m}$. The grouping of laths that form rods is visible when the fibres are observed at higher magnifications (Fig. 1e and f) and, as occurs in most sepiolites, the rods gather to form bundles (Fig. 1b, c and d). With TEM typical laths, the minor crystals, can be observed. The morphology of these laths is due to the good development of the $\{110\}$ prism faces. The sections of these laths range between 10-37 $\mathrm{nm}$ in width (Table 1). Aggregation of laths forms rods that can be observed in Fig. 2; these rods are between $80-150 \mathrm{~nm}$ in width.

Atomic-force microscopy was used to obtain a 3D approximation as a third method of studying sepiolite micromorphology. The fibrous morphology is shown in the lower magnification of the images (Fig. 4a), in which the variable length of these fibres can also be observed. As previously observed by SEM and TEM (see Figs. 1, 2 and 3 ), when AFM is used, the fibres (s.l.) appear as rods formed by other simpler units; it is sometimes possible to identify laths in these samples (Figs. 4, 5 and 6). The most common images obtained correspond to fibres (s.l.) in which steps are observed. These fibres are actually rods and the steps correspond to laths (Fig. 7). However, the two types of crystals (lath and rod) are not as easily distinguished in AFM compared to TEM. Although differentiating the laths was sometimes not possible, the width of the rods ranged between $40-250 \mathrm{~nm}$, and those of the laths ranged between 12 and $54 \mathrm{~nm}$ (Table 1).

Furthermore, to complete the 3D information, profiles of the particles can be obtained, similar to the ones shown in Fig. 5d. These profiles allow us to obtain precise values of

Table 1. Statistics of the lath width (in nm) obtained by AFM (from height and deflection images) and by HR-TEM.

\begin{tabular}{llll}
\hline & & RT-LATH-W & HT-LATH-W \\
\hline AFM & Max. & 54 & 25 \\
& Min. & 12 & 13 \\
& Mean & $\mathbf{2 1}$ & $\mathbf{1 9}$ \\
AFM (DEF) & St. dev. & 5 & 2 \\
& Max. & 40 & 29 \\
& Min. & 13 & 14 \\
& Mean & $\mathbf{2 2}$ & $\mathbf{1 9}$ \\
TEM & St. dev. & 4 & 3 \\
& Max. & 38 & 43 \\
& Min. & 10 & 9 \\
& Mean & $\mathbf{2 2}$ & $\mathbf{1 8}$ \\
& St dev. & 10 & 6 \\
\hline
\end{tabular}

the height of the particles (Fig. 7). The data obtained for the $\mathrm{H}_{\mathrm{R}}$ (rod height) are between 6.9-39.4 nm, whereas for the $\mathrm{H}_{\mathrm{L}}$ (lath height) they vary between $0.55-8.17 \mathrm{~nm}$. The ratio $\mathrm{W}_{\mathrm{R}} / \mathrm{H}_{\mathrm{L}}$ is equal to 3.2 as mean value, WR being the rod width.

\section{Folded sepiolite}

The structural change in the Grant County sepiolite, into a semi-anhydrous form (folded sepiolite) after heating, is easily observable from the diffraction patterns. The intensity of the main peak at $12 \AA$ in natural sepiolite, corresponding to a 110 reflection, decreases after heating to $350^{\circ} \mathrm{C}$, while two new reflections appear. These two new reflections appear at $10.4 \AA$ and $8.3 \AA$, and their intensity increases after heating to $450^{\circ} \mathrm{C}$; however, this temperature is not enough to complete the transformation of the mineral, and the sepiolite 110 reflection remains. The formation of the anhydrous phase is achieved after heating to $550^{\circ} \mathrm{C}$ and the 110 reflection of sepiolite at $12 \AA$ disappears, whereas the peaks of the semi-anhydrous phase appear at $11.72 \AA, 10.02 \AA$ and $8.02 \AA$. The variation in the position of these characteristic peaks of heated sepiolite were also observed by Hayashi et al. (1969) and Nagata et al. (1974), which is in agreement with the diminution of the cell parameter values also observed by Post et al. (2007) and Sánchez del Río et al. (2011).

The micromorphology of the folded sepiolite has been studied using TEM and AFM. The overall aspect of the heated fibres observed by these techniques is the same as that of the natural sample (Figs. 8 and 9). From their morphological features, it is not possible to differentiate the natural and heated sepiolite, using TEM or AFM. The fibres usually correspond to rods, but laths of variable lengths can be observed sometimes. The width of the individual laths measured with HR-TEM is variable, as with the natural sample, but smaller sections have been found in heated and folded sepiolite (see Table 1). Both the mean and minimum values of the fibre width after folding obtained by TEM are minor compared with those of the natural sample. The same occurs with data from AFM, the mean value of the fibre width decreased from $22 \mathrm{~nm}$ to 18.8 $\mathrm{nm}$ after heating and folding of the sepiolite.

\section{Discussion}

\section{Micromorphology of natural sepiolite}

Scanning electron microscopy is the most frequently used technique to study micromorphology and texture of clay minerals. For sepiolite, it allows obtaining the length and type of fibre, but the termination of the individual crystals cannot be clearly observed. The fibres observed by SEM correspond to rods, and it is not possible to measure the size of the laths. In this sample, the length of the fibres is variable, but frequently is more than $10 \mu \mathrm{m}$, corresponding to type 3, as described by García-Romero \& Suárez (2013). 

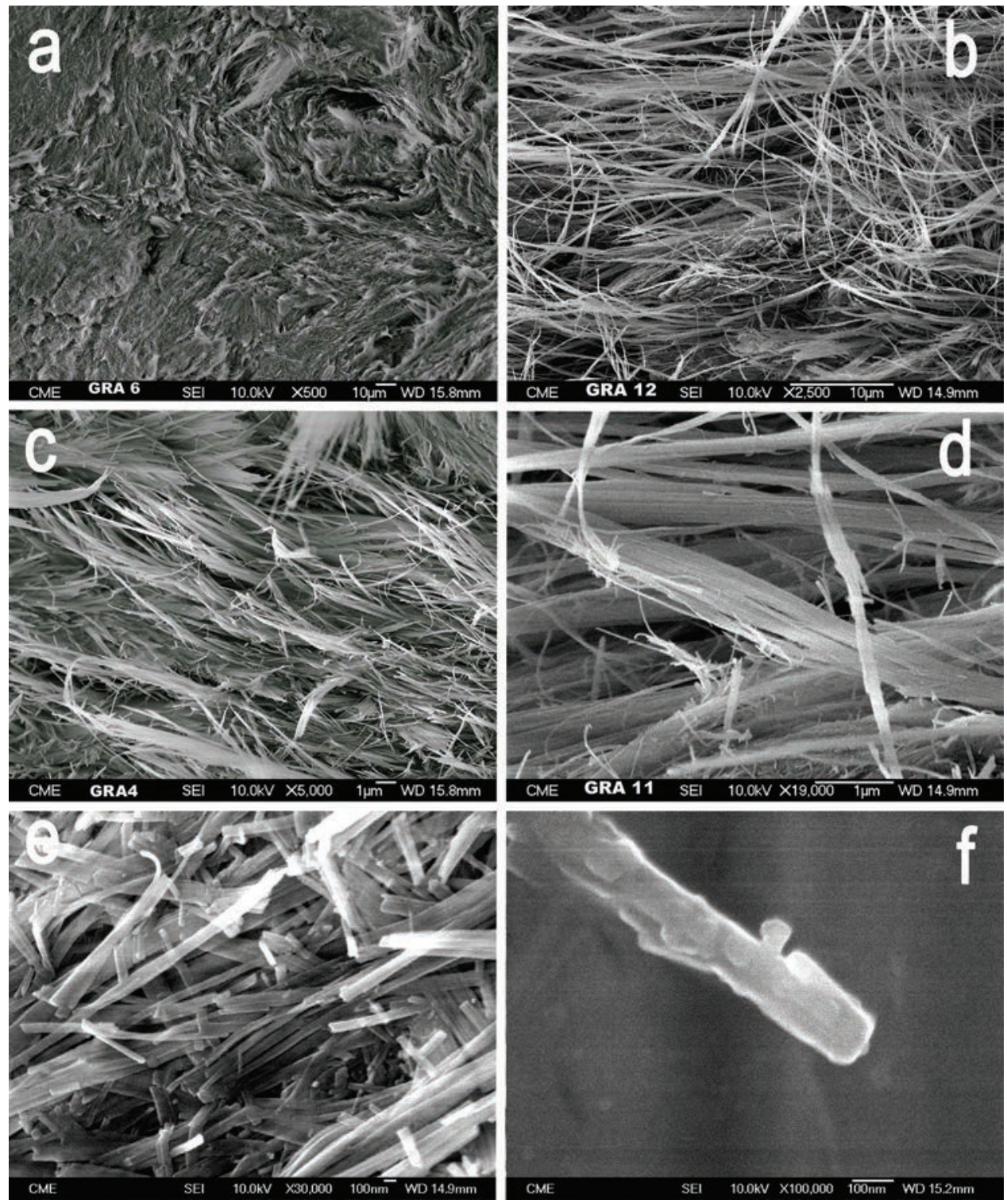

Fig. 1. Grant County sepiolite SEM-FEG images showing its fibrous morphology and very open texture (a, b, c and d). The length of the fibres (more than $10 \mu \mathrm{m}$ ) is observed in $\mathrm{b}$ and $\mathrm{c}$. Bundles of fibres are observed in $\mathrm{b}, \mathrm{c}$ and $\mathrm{d}$. The grouping of laths forming rods is visible in $\mathrm{e}$ and $\mathrm{f}$.

The size of the fibres and, specifically, the open texture are related to the low specific surface area of the Grant County sepiolite (Suárez \& García-Romero, 2012).

The use of TEM is required for achieving higher magnification of the fibres but the ordinary method of sample preparation by dispersion of a powder in n-butanol breaks the fibres and avoids the observation of textures. Therefore, this technique allows for studying the width of the laths and rods with more detail but not theirs lengths, as known. The rods are between $80-150 \mathrm{~nm}$ in width and are formed by laths with widths between $10-37 \mathrm{~nm}$. In the images obtained with the highest magnifications in TEM (Figs. 2 and 3), the fibre terminations are not clear; however, it seems that pinacoids could be the most frequent crystal form, in good agreement with Bastida et al. (2006). These authors calculated the central distances $\left(D_{h k l}\right)$ for different possible crystal forms of sepiolite and concluded that the most probable forms are in the parallel to [001] direction; the fibre axis, as with all sepiolites, has prevalent forms, the $\{110\}$ prism and the $\{010\}$ pinacoid, whereas the $\{100\}$ cannot be developed. The fibres formed by the prisms and pinacoids show smaller development, and the prevalent forms are the $\{011\}$ prism and the smaller $\{111\}$ dipyramid.

In the images of the individual crystals, the laths, it is not possible to identify the crystal form in the [001] direction; the pinacoid as the termination of the crystals could only be identified in a few laths. The irregular surfaces of the fibres sections (Fig. 3) may be caused by the dispersion and breaking of the fibres during the dispersion treatment; however, this is probably also representative of the natural crystal morphology (García-Romero \& Suárez, 2013, 


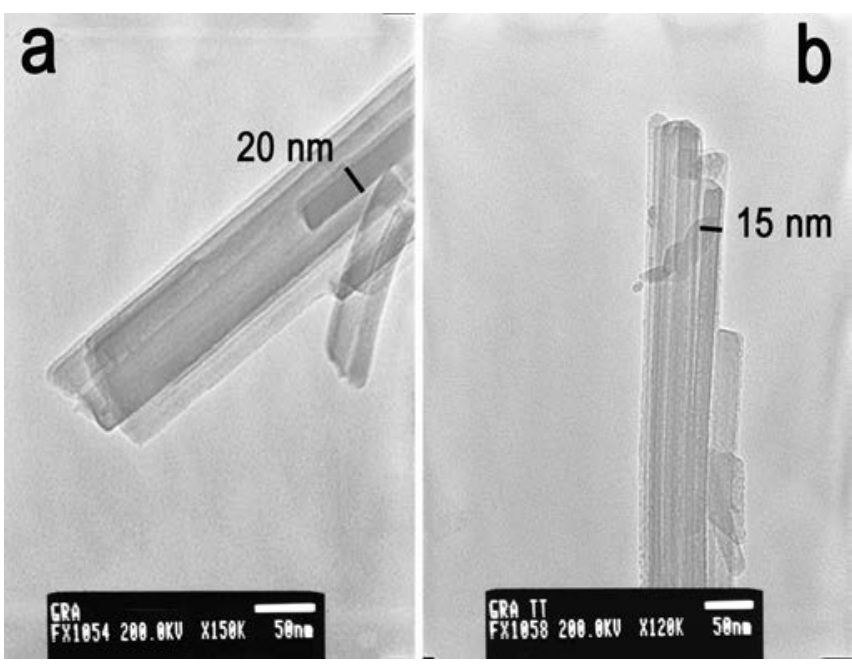

Fig. 2. Grant County sepiolite TEM images: (a) Laths of natural sample forming rods. (b) Rods of a heated sample formed by laths.

2014). The sepiolite crystals develop a fibrous morphology in the [001] direction because the $(h k 0)$ faces are F-faces (flat) without kinks, in which atoms cannot be incorporated, while the (001) faces are K-faces (kinked), in which the growth occurs rapidly by the addition of atoms. This growth leads to well-developed prismatic faces for $(h k 0)$ and an irregular growth surface on the section of fibres, which is mostly observed using HR-TEM (Fig. 3).

According to the AFM observations, there is great variability in the size of the fibres, both in length and width. The fibres vary from the broadest and shortest laths measured (Fig. 4b and c) that have prismatic, rather than fibrous characteristics, to the most frequent particles that have a greater length/width ratio and correspond to the typical fibres of sepiolite, such as those shown in Fig. 4a. It is not easy to observe individual crystals from the AFM images; however, when an exceptional crystal can be observed (Figs. 4c, 5 and 6), the $\{110\}$ prism and the $\{010\}$ pinacoid crystal forms can be identified. Regarding the termination of the fibres, very few images contain this valuable information; however, the presence of the dipyramid $\{111\}$ and pinacoid $\{001\}$ forms could be interpreted from some of the crystals (see Figs. 5 and 6). These crystal forms agree with the previously referred calculations of Bastida et al. (2006).

As mentioned above, by using AFM, it is possible to obtain not only more realistic 2D images (Figs. 4, 5a-b and $6 \mathrm{a}-\mathrm{b})$ but also to obtain 3D images in which the height of the rods or laths can be measured (Figs. 5 and 6).

When an AFM tip scans over a topographic feature that is steeper than the taper angle of the tip, the latter will lose
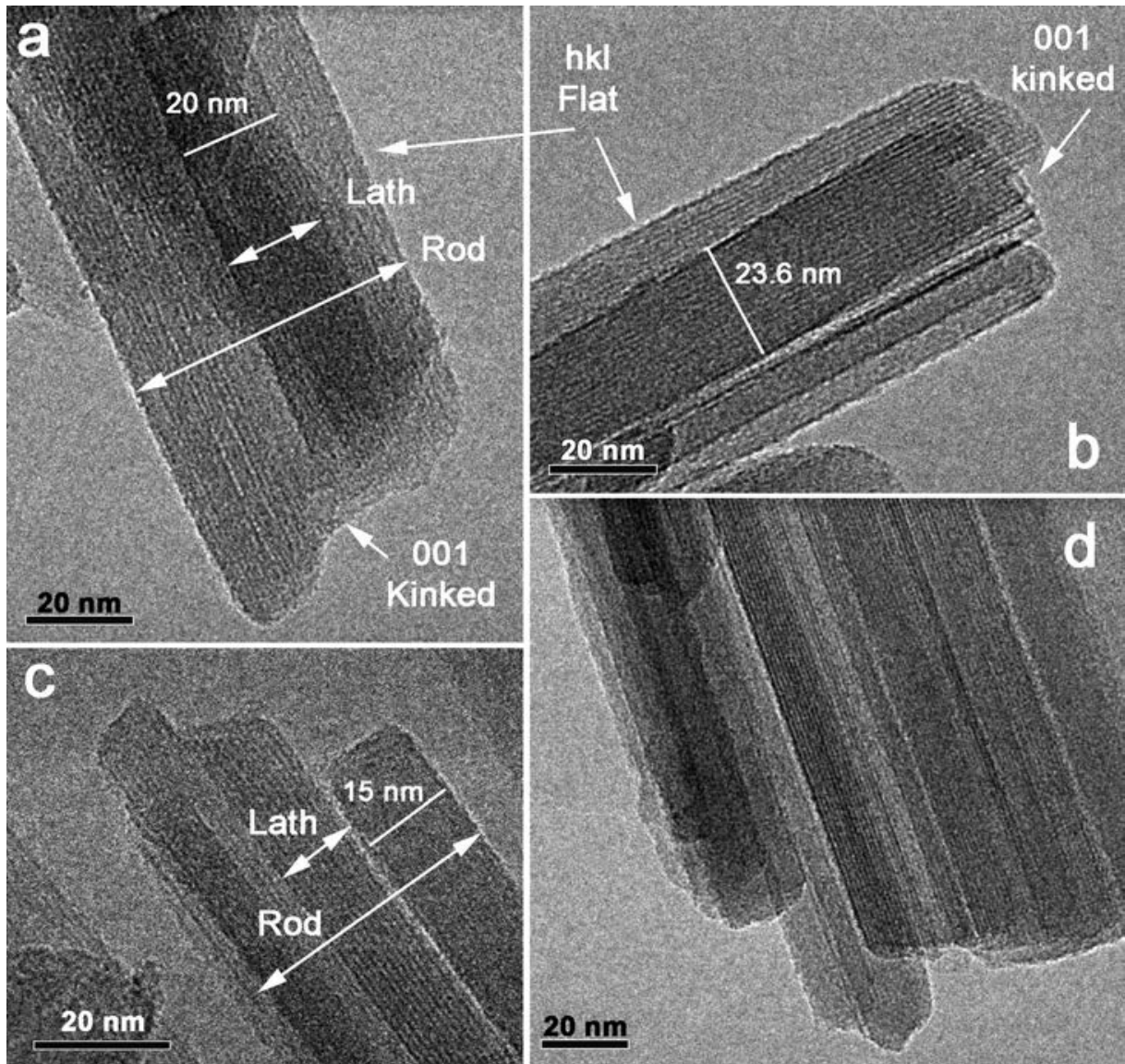

Fig. 3. Grant county sepiolite HR-TEM images of laths forming rods: a and b are the natural samples, $\mathrm{c}$ and $\mathrm{d}$ are the samples heated to $550^{\circ} \mathrm{C}$. 

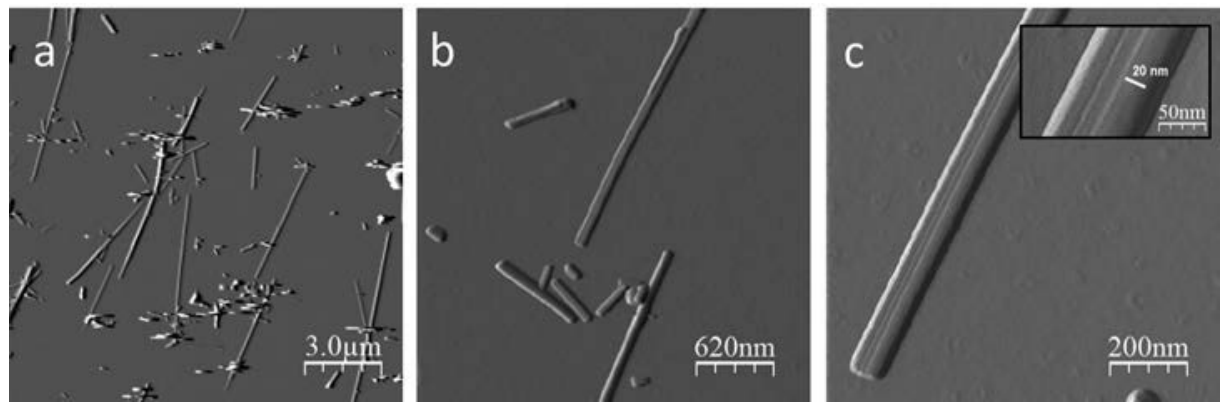

Fig. 4. Atomic-force microscopy (AFM) deflection images of natural sepiolite showing the fibre sizes. The width of the fibres ranges between 100 and $250 \mathrm{~nm}$ ( $\mathrm{a}$ and $\mathrm{b}$ ), whereas the individual laths range between $\sim 10-50 \mathrm{~nm}$ (c and inlet).
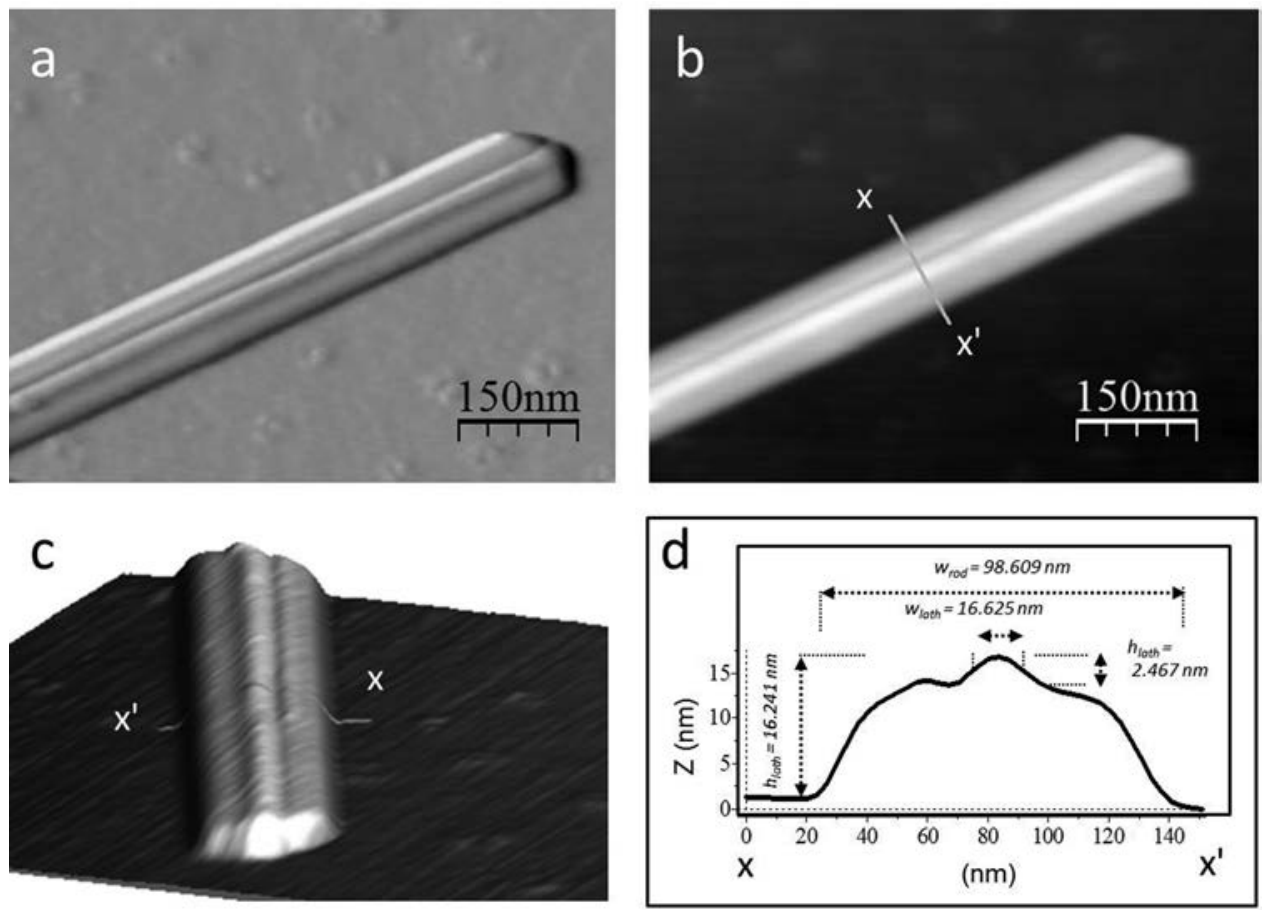

Fig. 5. AFM images of deflection (a), height (b) and a 3D model from a height image (c) of a single sepiolite rod. (d) height profile along the line $\mathrm{X}-\mathrm{X}$ '.

the contact with the sample surface, causing then a distortion of the image, a so called tip-sample convolution artifact (Eggleston, 1994). This phenomenon depends not only on the shape of the tip but also on the sample position $(c f$. Fig. 8). In order to normalize the measurements, the width of the bundles was taken in all cases from side to side at the fibre borders, which were visually identified at the inflection point between the mica substrate and the fibre particle, as shown in Figs. 5 and 6. However, the lath widths were measured at half of the maximum height of the last step shown on the top of the bundle (see profiles in Figs. 6 and 7). Independent laths could generally not be detected in the sample, although all of the fibres observed by means of AFM (corresponding to rods or bundles) showed stripes on both sides of the fibres, parallel to the fibre elongation. Moreover, the corresponding profiles perpendicular to the fibre showed steps with different widths. This finding led us to interpret those steps as laths (Figs. 4c and 5d). The width measurements of the height and deflection images of bundles, rods and laths were in good agreement.

The values obtained for the width of the fibres were similar with TEM and AFM, although there were fewer from AFM. These fibre width values were not equal from the two techniques and were probably, in both cases, slightly smaller than the actual values due to the orientation of the crystals, as is shown in Fig. 7. Sepiolite crystals mainly develop $\{110\}$ faces, as previously described and as can be observed in the scarce images of the (001) section of this mineral (Routureau \& Tchoubar, 1976; Krekeler \& Guggenheim, 2007; García-Romero \& Suárez, 2013). These types of elongated crystals lie on the $\{110\}$ faces, as in Fig. 7, and it is normally not possible to obtain a direct measure of the $\mathrm{W}_{\mathrm{L}}$ and $\mathrm{H}_{\mathrm{L}}$ (lath width and height) and the $\mathrm{W}_{\mathrm{R}}$ and $\mathrm{H}_{\mathrm{R}}$ (rod width and height) because these 

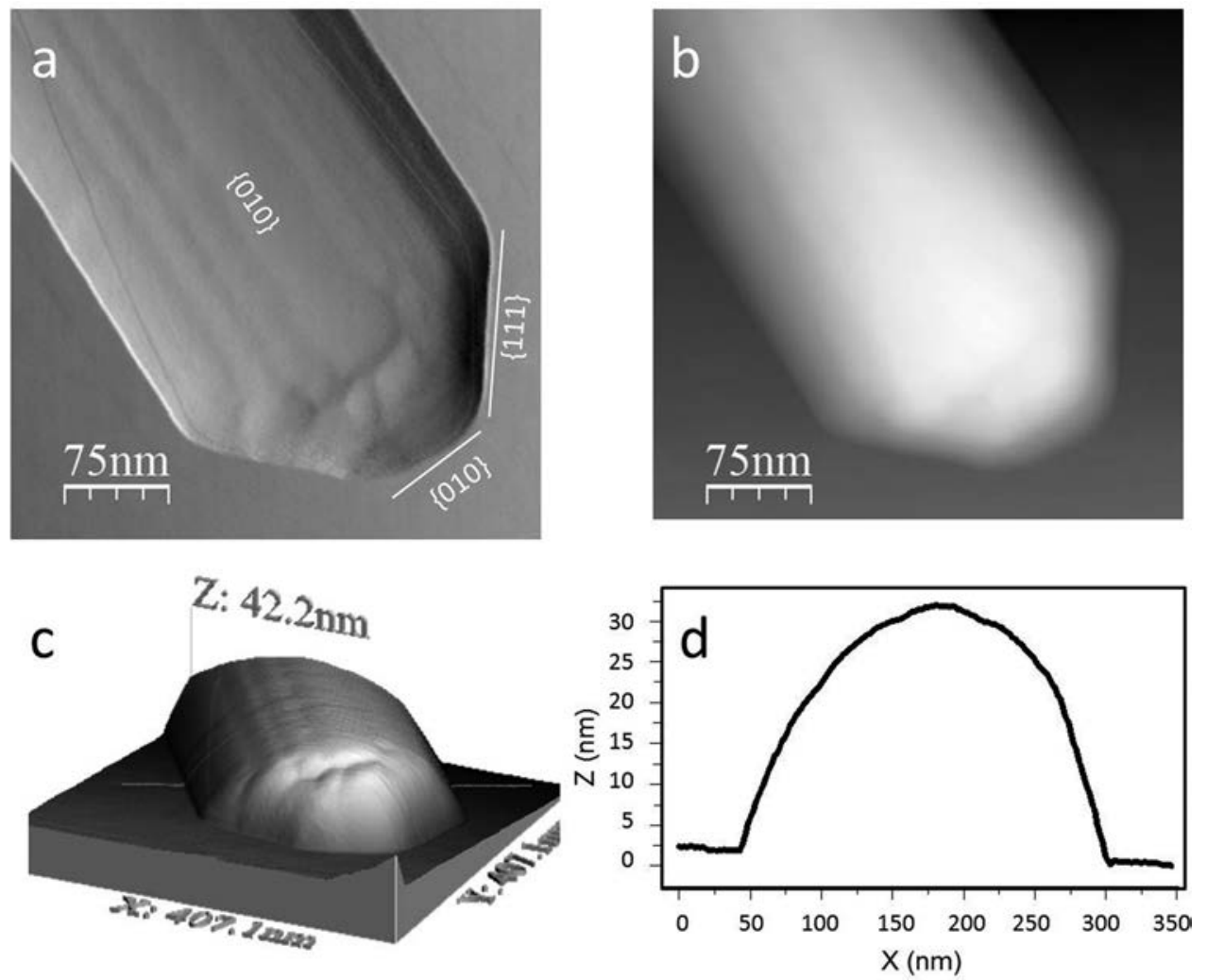

Fig. 6. AFM images of deflection (a) and height (b) showing forms that can be interpreted as dipyramid $\{111\}$ and pinacoid $\{010\}$. 3D models (c) and profiles of the particles (d) were calculated to complete the information.
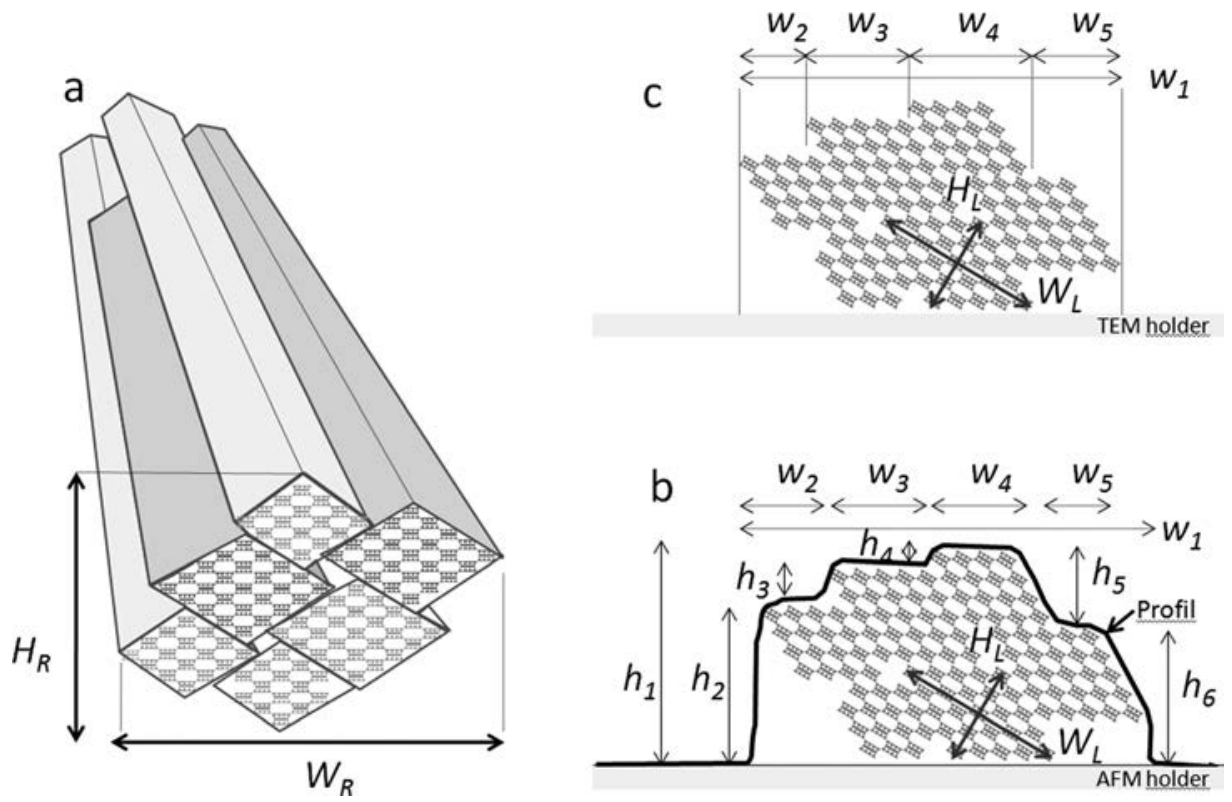

Fig. 7. Scheme showing a sepiolite crystal and the different measures that can be performed depending on the technique used, TEM or AFM.

dimensions are never parallel to the sample holder. Furthermore, the fibres that can be observed are mesocrystals or rods formed by aggregation of individual crystals or laths (García-Romero \& Suárez, 2013, 2014). The values, $\sim 20-22 \mathrm{~nm}$, correspond to the mean of the accessible $\{110\}$ faces. In some cases, they correspond to the full faces ( $w_{3}$ in Fig. $7 b-c$ and $w_{4}$ in Fig. $7 b-c$ ), but in some cases they are only a portion of one face $\left(w_{2}\right.$ in Fig. $7 b-c$ 
and $\mathrm{w}_{5}$ in Fig. $\left.7 b\right)$ or more than one face $\left(\mathrm{w}_{4}\right.$ and $\mathrm{w}_{5}$ in Fig. $7 \mathrm{c}$ ) in others. This phenomenon and the fact that obviously not all individual crystals are equal produce a wide dispersion of the data (Table 1); however, the mean value gives a good approximation of the range of the measurement.

The profiles obtained allow one to measure not only the width but also of the height of the particles (Fig. 7), and to realize that the mesocrystals are tabular $\left(\mathrm{W}_{\mathrm{R}} / \mathrm{H}_{\mathrm{L}} \sim 3.2\right)$. The mean value of the $\mathrm{H}_{\mathrm{R}}(31.6 \pm 7.6 \mathrm{~nm})$ indicates that the crystals aggregate mainly in the [010] direction. For the values obtained for $\mathrm{H}_{\mathrm{L}}$ the same concern exists as for the width. In Fig. 7c, the height of the steps is shown $\left(\mathrm{H}_{2}\right.$ to $\mathrm{H}_{6}$ ), which does not correspond to the $\mathrm{H}_{\mathrm{L}}$; in this case, most of the values are much smaller than the $\mathrm{H}_{\mathrm{L}}$.

\section{Micromorphology of the heated sepiolite}

Heating the natural sample was undertaken to evaluate whether the change in the structure by folding could influence the morphology of the crystals. The heating of sepiolite to over $350^{\circ} \mathrm{C}$ produced a transformation into the semianhydrous form, which was followed by folding of the structure. A change in the sepiolite structure by dehydration and folding into a more stable structure involves a variable reduction in the volume, depending on the temperature of heating, which can reach $28 \%$ after heating at $675^{\circ} \mathrm{C}$, according to Post et al. (2007), who studied a sepiolite from Durango (Mexico). The change in volume could be detected from a study using AFM and HR-TEM.

The HR-TEM images from the Grant County sepiolite, including the natural and heated sample, allow for a precise measurement of the $d$-spacing and evaluation of the changes in the structure as a consequence of heating and dehydration (Fig. 8a and b). While the expected values were approximately $1.2 \mathrm{~nm}$, corresponding to the (110) plane, for the natural sample, lower $d$-spacing was found in the heated sample $(1.17$ and $1.04 \mathrm{~nm})$, in good agreement with data obtained from the XRD patterns. The new $d$-spacing, at $1.04 \mathrm{~nm}$, was observable with the HR-TEM image of the folded sepiolite (Fig. 8b). The width of the laths decreases after folding, both the minimum and mean value according to the diminution of volume addressed by Sánchez del Río et al. (2011).

The results of the AFM study are similar, no micromorphological differences between the natural and heated samples have been found; however, the mean values of the lath widths are less than those of the natural sample if the measures from profiles and from deflection are considered. As for the natural samples, the fibres observed with AFM correspond to bundles and, primarily, to rods (Fig. 9).

There is good agreement among the three evaluated measurements (Table 1), both for the natural and heated sample. Although the maximum and minimum values of the lath widths are variable, the mean width of these laths, or individual crystals, is approximately the same, independently of the technique (TEM or AFM) or method (intensity profiles or distances in deflection images in AFM)
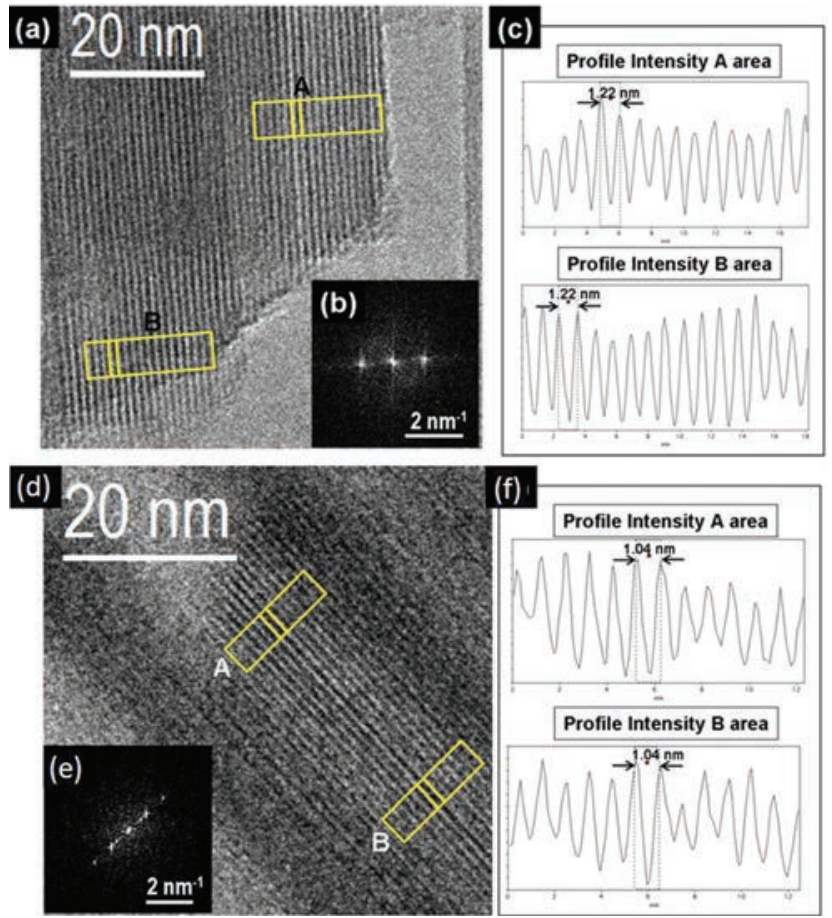

Fig. 8. (a) HR-TEM image of Grant County sepiolite natural sample and (b) corresponding Fourier transform. In (c) the intensity profiles corresponding to the yellow lines reveals the characteristic (110) $d$-spacing at $1.2 \mathrm{~nm}$. (d) HR-TEM image of folded sepiolite and corresponding (e) Fourier transform. (f) Intensity profiles of the yellow marked areas revealing (110) $d$-spacing at $1.04 \mathrm{~nm}$. (online version in colour)

used. In all cases, the mean values of the natural sample laths are $\sim 21.5 \mathrm{~nm}$ in width, whereas this value decreases by $\sim 18.5 \mathrm{~nm}$ after heating. This indicates an $\sim 15 \%$ reduction, which is in good agreement with the reduction in cell parameters observed by Post et al. (2007), who found that both the $a$ and $b$ parameter decreased by $\sim 15 \%$ after heating and folding the natural sepiolite. These measures indicated that both techniques, the TEM and AFM, are sensitive to a change in the size of the fibres, which is associated with a phase change due to the release of all of the zeolitic water and half of the coordinated (or bounded) water.

\section{Final remarks}

In this study, we show how using images obtained from different electronic microscopies, such as SEM-FEG, TEM and AFM, improves the definition of the particle size of sepiolite.

Both the HR-TEM and AFM techniques provide an approximation of the fibre width values because the aggregation of the individual crystals and the orientation of the particles prevent the ability to measure the dimension of the individual laths. Although the values obtained from the two techniques are similar, those obtained by the HR-TEM are more accurate. 

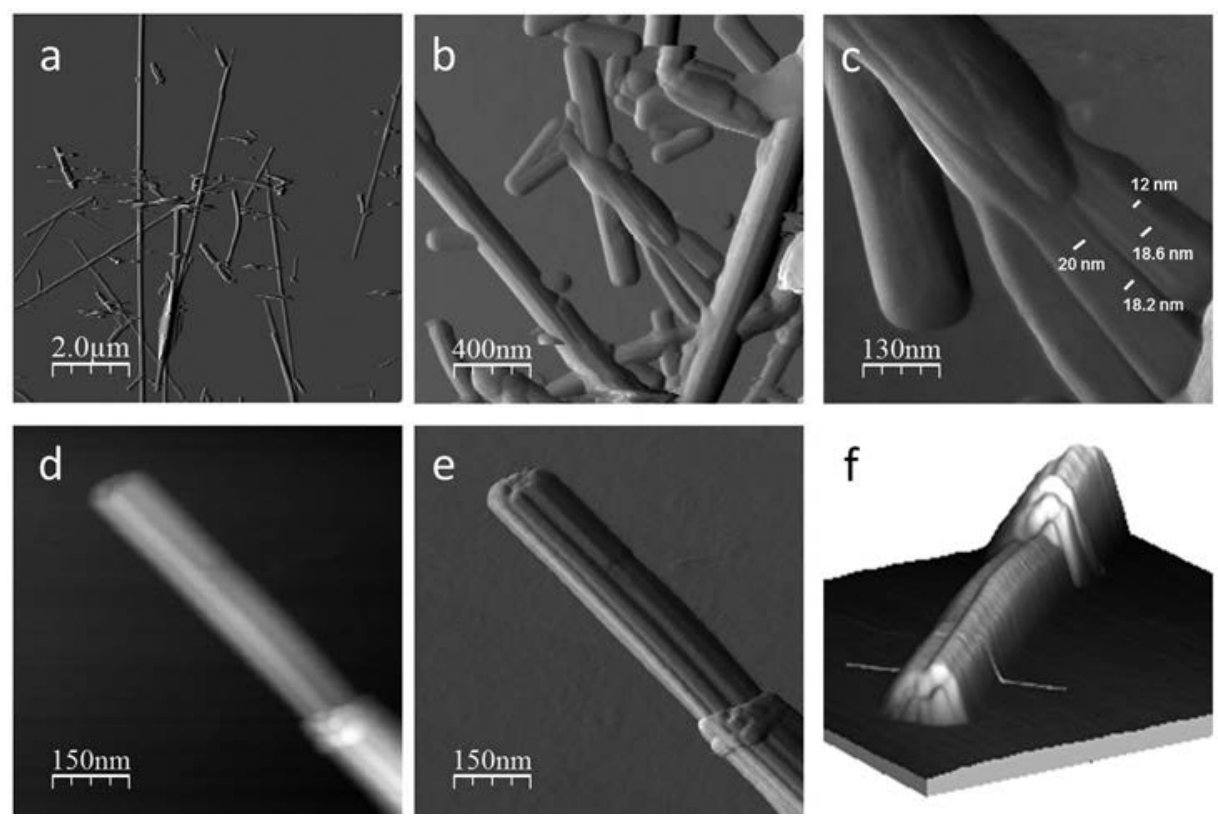

Fig. 9. Images obtained with AFM of thermally treated sepiolite samples. Observations (a) to (c) show deflection images at different scales. Although the micromorphology of the fibres does not differ from the natural samples, the particle width decreases by $\sim 15 \%$. The height (d), deflection (e) and 3D model AFM images of one rod are also shown.

The AFM has been shown to be a very useful and powerful technique for analysing particle size at the submicrometre range of special minerals, such as sepiolites, which provides, after image processing, a 3D perspective that represents the sepiolite particles. By this technique the tabular morphology of the rods has been shown.

The folding of the structure after heating to over $500^{\circ} \mathrm{C}$ has been followed by XRD and the precise measures performed by HR-TEM and AFM on the heated and folded samples show the micromorphological change in the particles that decrease in size according to the diminution of the unit cell.

Acknowledgements: The comments of the two anonymous reviewers are gratefully acknowledged, as well as financial support by MINECO (CGL2012-35475). Research by A.T.P. has been also supported by a PICATA postdoctoral fellowship of the Moncloa Campus of International Excellence (UCM).

\section{References}

Alkan, M. \& Benlikaya, R. (2008): Poly(vinyl alcohol) nanocomposites with sepiolite and heat-treated sepiolites. J. Appl. Polymer Sci., 6, 3764-3774.

Álvarez, A., Santarén, J., Esteban-Cubillo, A., Aparicio, P. (2011): Current industrial applications of palygorskite and sepiolite. in "Developments in palygorskite-sepiolite research", E. Galán \& A. Singer, eds. Dev. Clay Sci., 3, Elsevier. 2011, 281-298.

Bastida, J., Kojdecki, M.A., Pardo, P., Amorós, P. (2006): X-Ray diffraction line broadening on vibrating dry milled Two Crows sepiolite. Clays Clay Minerals, 54, 390-401.
Benli, B., Du, H., Celik, M.S. (2012): The anisotropic characteristics of natural fibrous sepiolite as revealed by contact angle, surface free energy, AFM and molecular dynamics simulation. Coll. Surf. A: Physicochem. Eng. Aspects, 408, 22-31.

Brauner, K. \& Preisinger, A. (1956): Struktur und Entstehung des Sepioliths. Tschermaks Mineral. Petrogr. Mitt., 6, 120-140.

Bukas, V.J., Tsampodimou, M., Gionis, V., Chryssikos, G.D. (2013): Synchronous ATR infrared and NIR-spectroscopy investigation of sepiolite upon drying. Vibrat. Spect., 68, 51-60.

Can, M.F., Çınar, M., Benli, B., Özdemir, O., Çelik, M.S. (2010): Determining the fiber size of nano structured sepiolite using Atomic Force Microscopy (AFM). App. Clay Sci., 47, 217-222.

Eggleston, C.M. (1994): High-resolution scanning probe microscopy: Tip-surface interaction, artifacts, and applications in mineralogy and geochemistry. in "Scanning probe microscopy of clay minerals.", KL. Nagy \& AE. Blum, eds. CMS workshop lectures vol. 7. Boulder, CO. Clay Miner Soc., 3-90.

Frost, R.L. \& Ding, Z. (2003): Controlled rate thermal analysis and differential scanning calorimetry of sepiolites and palygorskites. Thermochim. Acta, 397, 119-128.

García-Romero, E. \& Suárez, M. (2010): On the chemical composition of sepiolite and palygorskite. Clays Clay Minerals, 58, $1-20$.

—, - (2013): Sepiolite-palygorskite: textural study and genetic considerations. Appl. Clay Sci., 68, 129-144.

—, - (2014): Oriented aggregation as a crystal growth mechanism in natural environments (the sepiolite-palygorskite polysomatic series). Am. Mineral., 99.

Hayashi, H., Otsuka, R., Iman, N. (1969): Infrared study of sepiolite and palygorskite on heating. Am. Mineral., 54, 1613-1624.

Horcas, I., Fernandez, R., Gómez-Rodriguez, J.M., Colchero, J., Gómez-Herrero, J., Baro, A.M. (2007): WSXM: a software for scanning probe microscopy and a tool for nanotechnology. Rev. Sci. Instrum., 78, 013705 . 
Krekeler, M.P.S. \& Guggenheim, S. (2007): Defects in microstructure in palygorskite-sepiolite minerals: a transmission electron microscopy (TEM) study. App. Clay Sci., 39, 98-105.

Miltner, H.E., Watzeels, N., Gotzen, N.A., Goffin, A.L., Duquesne, E., Benali, S., Ruelle, B., Peeterbroeck, S., Dubois, P., Goderis, B., Van Assche, G., Rahier, H., Van Mele, B. (2012): The effect of nano-sized filler particles on the crystalline-amorphous interphase and thermal properties in polyester nanocomposite. Polymer, 53, 1494-1506.

Nagata, H., Shimoda, S., Sudo, T. (1974): On dehydration of bound water of sepiolite. Clays Clay Minerals, 22(285), 293.

Ökte, N. \& Sayinsöz, E. (2008): Characterization and photocatalytic activity of $\mathrm{TiO}_{2}$ supported sepiolite catalysts. Sep. Purif. Tech., 62, 535-543.

Pinner, R.D., Xu, T.T., Fisher, F.T., Qiao, Y., Rioff, R.S. (2003): Atomic force microscopy study of clay nanoplatelets and their impurities. Langmuir, 19, 7995-8001.

Post, J.E., Bush, D.L., Heaney, P.J. (2007): Synchrotron powder Xray diffraction study of the structure and dehydration behaviour of sepiolite. Am. Mineral., 92, 91-97.

Routureau, M. \& Tchoubar, D. (1976): Structural analysis of sepiolite by selected electron diffraction-relations with physico-chemical properties. Clays Clay Minerals, 24, 43-49.
Ruiz-Hitzky, E., Aranda, P., Álvarez, A., Santarén, J., EstebanCubillo, A. (2011): Advanced materials and new applications of sepiolite and palygorskite. in "Developments in palygorskitesepiolite research", E. Galán \& A. Singer, eds. Chapter 17. Dev. Clay Sci., 3, Elsevier, 293-452.

Sánchez del Río, M., García-Romero, E., Suárez, M., da Silva, I., Fuentes Montero, L., Martínez-Criado, G. (2011): Variability in sepiolite: diffraction studies. Am. Mineral., 94, 200-203.

Suárez, M. \& García-Romero, M. (2011): Advances in the crystal chemistry of sepiolite and palygorskite. in "Developments in palygorskite-sepiolite research. A new look at these materials", E. Galán \& A. Singer, eds. Dev. Clay Sci., 3, Elsevier. 2011, 33-65.

—, - (2012): Variability of the surface properties of sepiolite. Appl. Clay Sci., 67, 72-82.

_, _ (2013): Sepiolite-palygorskite: a continuous polysomatic series. Clays Clay Minerals, 61, 461-475.

Received 3 March 2014

Modified version received 29 July 2014

Accepted 12 September 2014 